\title{
Assessment of the early level of distance education effectiveness
}

\author{
Kseniya Melnikova ${ }^{1, *}$, Lyudmila Tyukina ${ }^{1}$, and Vladimir Babayan ${ }^{2}$ \\ ${ }^{1}$ Yaroslavl State Technical University, Yaroslavl, Russian Federation \\ ${ }^{2}$ Yaroslavl Higher Military Institute of the Air Defense, Yaroslavl, Russian Federation
}

\begin{abstract}
Nowadays digital education is the one of the main parts of our life. The pandemic situation influenced greatly on digitalization of Russian higher education. Some of higher educational institutions weren't ready for digital educational activity. This paper concerns the problem of the start of the implementation of digital education at Higher Educational Institutions. The aim of the study is to assess the efficiency of digital education at YSTU in period of the beginning of distance learning. The survey of students revealed in May, 2020, along with the defining of different types of training and the attempts to describe the factors effect on the results of the study. As a methodology we used quantitative research methods, namely, anonymous questionnaires of 204 students of the 1st and 2nd years of YSTU. The survey was conducted one month after the start of distance learning. The results can be used for statistical analysis carried out within the framework of the education reform.
\end{abstract}

\section{Introduction}

There has been a lot of talk about the development of digital education in recent years. And the topic is highly relevant, as the digital transformation of society is inevitable. This problem was particularly acute in March 2020, since the pandemic of the coronavirus COVID - 19 forced all higher educational institutions of the Russian Federation to switch to online training mode, remote or electronic, e-Learning.

The use of computer technology in the teaching of foreign languages is not only a common phenomenon but also a requisite of the times, especially due to the recent developments in the modern world of globalization. Many different works are devoted to this problem $[1,4,5,6,8,9,11,12,14,15]$, since interactive learning with the use of multimedia programs contribute to solving many pedagogical, methodological, didactic, and psychological problems simultaneously, and turns the learning process into a more effective, interesting and creative activity for students [1].

E-Learning is a modern complement to, and sometimes even an alternative to, traditional education. It allows learning at a very high level, available anywhere and anytime. The use of specially prepared teaching materials such as syllabi, lectures, interactive exercises, electronic tutorials, videos, and many other multimedia materials make this learning effective, as well as increase students' motivation to learn a foreign language.

\footnotetext{
* Corresponding author: ledeja@yandex.ru
} 
The term e-Learning appeared in 1999 in Los Angeles at a CBT Systems (Computer Based Training) workshop [2]. Even though almost 15 years have passed, there is still no single definition of e-Learning that most experts would accept. Most often, e-Learning is understood as learning that is built with the use of Internet technologies. For example eLearning - the use of the Internet - technologies to provide a wide range of solutions to improve knowledge and productivity [3]. E-Learning is based on fundamental principles such as:

- work is carried out over a network;

- delivery of educational content to the end-user is carried out through a computer using Internet technologies.

There is a definition given to this phenomenon by UNESCO specialists: "e-Learning learning with the help of the Internet and multimedia" [3]. Other definitions emphasize other aspects of e-Learning. For example, e-Learning - learning, built using information and telecommunication technologies and covering the whole range of activities, from the support of the learning process to the delivery of learning content to students [4]. The Law "On Education in the Russian Federation" contains Article 16: "Implementation of educational programs using electronic learning and distance learning technologies". It should be noted that e-Learning is the organization of educational activities using the information contained in databases and used in the implementation of educational programs, information processing technologies, technical means, as well as the use of information and telecommunication networks to ensure the transfer of this information and the interaction of students and teachers [5]. Under distance learning technologies are understood educational technologies implemented mainly with information and telecommunication networks in the indirect (at a distance) interaction of students and teachers. Organizations that carry out educational activities shall have the right to use e-Learning, distance learning technologies in the implementation of educational programs following the procedure established by the federal executive body responsible for the development of state policy and normative-legal regulation in the field of education [6].

Thus, we can conclude that e-Learning there are two types. The first type is the distance learning mode. This regime eliminates the physical presence of the instructor and students in the classroom. The source of learning material is actually a computer or other device (tablet, smartphone, etc.) connected to the Internet. The second type is what is known as "blended learning". E-Learning is used here as a tool to support the core learning process. In parallel with the e-Learning, classes are held traditionally, with the physical presence of teachers and students in the classroom. E-Learning allows the teacher and the student to choose the preferred format for the educational process. To summarize, both e-Learning modes are regulated by the legislation of the Russian Federation and have found their application in the educational process [7]

Due to the actions of the Ministry of Education of the Russian Federation and the management of Yaroslavl State Technical University (YSTU), Yaroslavl, Russia, to prevent the spread of the COVID - 19 coronavirus infection, YSTU switched over to distance learning on March 16, 2020. On March 19, 2020, the teachers of the Foreign Languages Department (FLD) conducted the first classes online using Microsoft's TEAMS platform.

\section{Methods}

Since the object of the study is the effectiveness of the learning process at YSTU in general and at FLD in particular, we need to identify the main factors of the effectiveness of educational activities.

According to previous studies, the main factors for the effectiveness of the learning process are:[8] 
1. technical equipment of the process, motivation for learning, time management in learning, the level of discipline teaching in the educational institution $[9,10]$.

Many contemporary scholars have noted that [10] that learners' evaluation of the quality, reliability, and ease of use of the learning system leads to its effectiveness. Some [11] emphasized that student computer literacy and time management are crucial in distance learning and concluded that the same factors apply to online learning. This statement is supported by research [12], which summarizes that for e-Learning to be effective, learners must have time management skills, i.e. time management and computer literacy skills. In eLearning, students can carry out online communication in student-student and studentteacher mode through chat rooms, e-mail, various social networks and applications. This support from fellow students and faculty members serves as a tool to increase the student's motivation to learn [13]. Studies show that high motivation of students leads to higher performance of learners, as well as increases the level of engagement and, consequently, motivation to learn the subject [14]. Many studies show that less motivated students perform poorly on tests, while those who are highly motivated to learn demonstrate higher academic achievement [15]. Other researchers conclude that student interest as a motivation factor promotes student engagement in learning, leads to improved learning effectiveness in eLearning $[16,17]$.

On May 25, 2020, a questionnaire survey was conducted among the 1st and 2nd-year students of YSTU. A total of 204 people took part in the survey. Respondents ranged in age from 17 to 19. The survey was conducted online using GOOGLE forms. The effectiveness of teaching at YSTU in general and the training activities of teachers of the Department of Foreign Languages, in particular, were assessed. The following groups of questions were posed to the students:

1) Has the level of comfort with learning changed? When answering this question, respondents were asked to be guided by methodological recommendations taking into account the following criteria: comfortable/uncomfortable with online learning; increased/decreased amount of free time;

2) Has their level of motivation to learn changed? When answering this question, respondents were asked to be guided by methodological recommendations taking into account the following criteria: like/dislike to study online; availability/absence of technical possibility to study online;

3) Has the level of study load changed? When answering this question, respondents were asked to be guided by methodological guidelines taking into account the following criteria: changed/unchanged amount of homework; changed/unchanged level of class workload (we mean online classes);

4) Has the level of online teaching changed? When answering this question, respondents were asked to be guided by methodological guidelines taking into account the following criteria: teacher's digital skills correspond/not correspond to the level of teaching. 


\section{Results}

The results are shown in Figure 1.

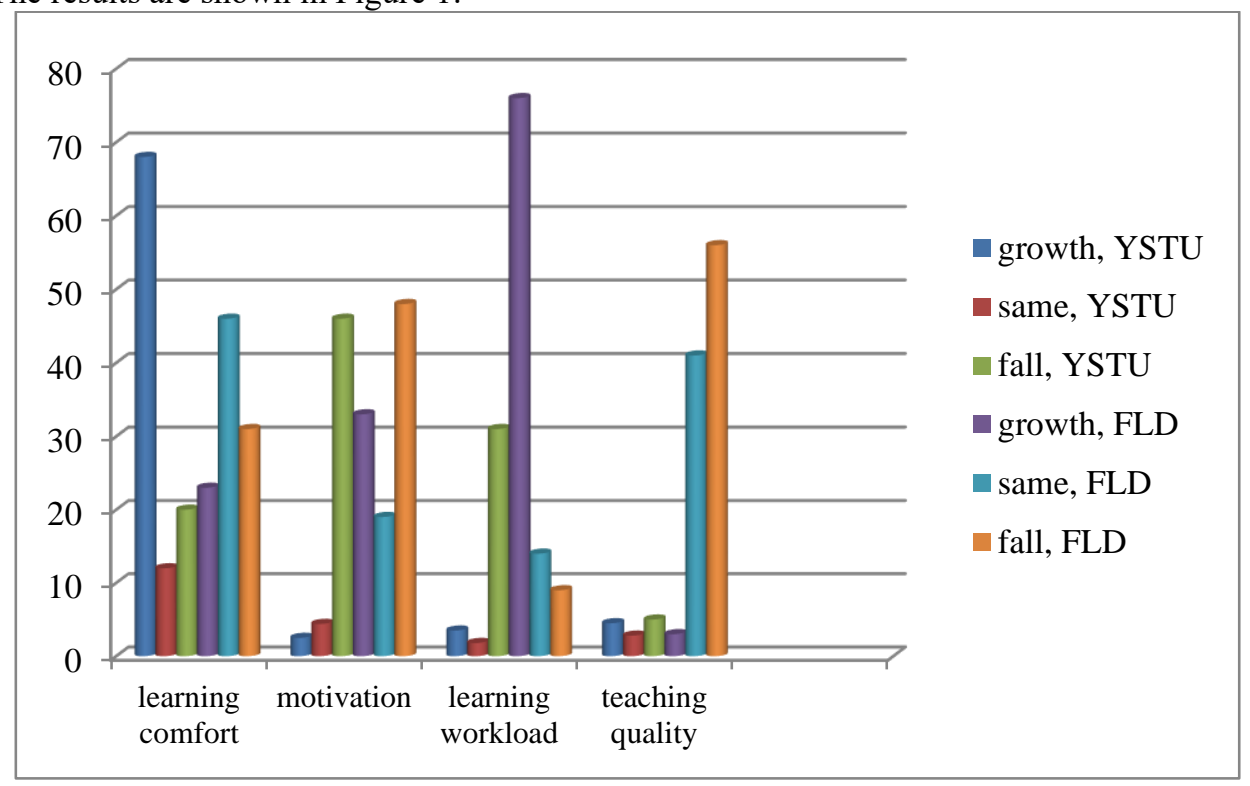

Fig. 1. Assessment of levels of e-Learning, \%.

Based on the data of the analysis, the level of comfort for students has increased significantly for HEIs - 138 people (68\%) out of 204 responded that the level of comfort, in general, has increased, 25 people (12\%) indicated that the indicators have not changed, 41 respondents $(20 \%)$ noted a decrease in the level of comfort. This is directly related to the work and rest mode of students. Since students don't have to spend time getting to and attending classes in real-time, there are more opportunities for students to get a good night's sleep and prepare for classes. Also, students have less stressful situations related to real-time assignments because they can always rely on other students, experts, and the internet for help.

In the Department of Foreign Languages, 47 respondents $(23 \%)$ increased the level of comfort in learning a foreign language, a decrease - 63 respondents (31\%), 94 respondents $(46 \%)$ noted that the level of comfort in learning a foreign language remains at the same level. The retention rate is since most of the faculty in the Foreign Language Department quickly transitioned to online learning and began teaching classes online as early as March 19, 2020.

The indicators of the level of motivation to study for the university as a whole and for the Department of Foreign Languages reflect a significant decrease. 116 (HEI) and 98 (FLD) respondents, respectively, which is expressed by $57 \%$ and $48 \%$. The decrease of this indicator is related to the large volume of assigned material for self-study. Students simply did not have time to complete all the assignments. As they had not only to perform practical tasks but also to study the theoretical part on their own. The absence of the need for physical presence in the classroom also leads to the relaxation of students and a decrease in their desire and need to perform tasks, leading to a decrease in motivation levels.

Indicators of increased motivation to learn are 74 respondents for HEI (36\%) and 67 for FLD (33\%). The level of motivation remains the same for 43 people $(21 \%)$ in the FLD and 39 respondents (19\%) in the FLD. Indicators close in value can speak about the total number of highly motivated students in HEIs. 
Respondents noted a significant increase in the level of training load both at the university as a whole - 165 respondents $(81 \%)$, and when studying a foreign language - 155 respondents $(76 \%)$. A decrease in teaching load index was 20 , and 18 respondents $(10 \%$ and $9 \%)$ for HEI and FLD, respectively. $18(9 \%)$ and $28(14 \%)$ respondents indicated maintaining the teaching load index at the same level.

\section{Discussion}

The significant increase is due to the unpreparedness, and often the inability, of many teachers to teach online. Unfortunately, not all YSTU teachers were able to quickly and qualitatively switch to online learning mode. Lack of materials in digital formats, inability to use software and equipment resulted in teachers sending students vast amounts of assignments for independent study. Both the theoretical part and the practical part students had to do on their own and send to the instructor. By these actions, some instructors compensated for the absence of online classes with students. The students could not cope with such volumes. Not surprisingly, this research indicator has increased significantly.

The FLD decreased by $84 \%$ and the FLD decreased by $56 \%$. This was noted by 171 and 114 respondents respectively. This indicator is directly related to the previous one. The same reasons are forcing students to note a decline in teaching. Only 29 (14\%) respondents note that the level of teaching across the university has remained at the same level. However, the figure for the Department of linguistics is much higher - 83 respondents $(41 \%)$. This is since many FLD teachers quickly converted to online teaching and began teaching classes online as early as March 19, 2020.

\section{Conclusion and recommendations}

Thus, we can conclude that in general, for the university in 2 months after the transition to distance learning in YSTU, there was a significant increase in the level of academic load along with a decrease in the level of student motivation for learning and reduction in the level of teaching disciplines. The author plans to conduct further research to see the results in dynamics. Along with this, it can be concluded that most university teachers were not ready for the transition to online mode, as well as students. The reasons why FLD teachers adapted faster to the changed situation are:

1) digital competencies of FLD teachers. This tool has proven to be extremely important, as many teachers actively conduct classes using multimedia tools. Therefore, registering and conducting classes using the MOODLE platform and TEAMS was not difficult for them.

2) some FLD teachers have interdisciplinary competencies (IT Master's Degree) and helped other teachers to adapt faster to their new online mode by conducting masterclasses and consulting sessions. This, in turn, allowed the FLD teachers to adapt faster to the new training conditions and produce the educational process at the proper level.

\section{References}

1. V. N. Babayan, Bulletin of the Yaroslavl Higher Military School of Air Defense: scientific journal 1(1), 21 (2017)

2. V. N. Babayan, Linguodidactics in a non-linguistic university: traditional and innovative approaches: collection of scientific articles, 168 (2019)

3. K.A. Melnikova, The Newman in Foreign Policy, 45(89), 30 (2018)

4. Open and Distance Learning: Trends, Policies and Strategies, 139 (2004) 
5. L. A. Tyukina, Linguodidactics in a non-linguistic university: traditional and innovative approaches: collection of scientific articles, 138 (2019)

6. L. A. Tyukina, Professionally oriented translation: reality and prospects: collection of scientific papers, 296 (2017)

7. L. Tyukina, V. Babayan, M. Lazović, SHS Web of Conferences 88 (2020)

8. K. Melnikova, A. Guslyakova, SHS Web of Conferences 88 (2020)

9. M. Justice Kintu, Ch. Zhu, Ed. Kagambe, International Journal of Educational Technology in Higher Education 14 (2017)

10. T. Anderson, Theory and Practice of Online Learning (2004)

11. E. Loukis, S. Georgiou, K. Pazalo, A value flow model for the evaluation of an e-learning service, ECIS (2007)

12. K. A. Pituch, Y. K. Lee, Computers \& Education 47(2), 222 (2006)

13. H. M. Selim, Computers \& Education 49(2), 396 (2007)

14. R. Lynch, M. Dembo, The International Review of Research in Open and Distributed Learning 5(2), 1 (2004)

15. R. Menager-Beeley, Web-based distance learning in a community college: The influence of task values on task choice, retention and commitment (Doctoral dissertation, University of Southern California) Dissertation Abstracts International, 64(9-A), 3191 (2004).

16. D. Abubakar, Adetimirin. Influence of computer literacy on post-graduates' use of eresources in Nigerian University Libraries. Library Philosophy and Practice. From http: //digitalcommons. unl. edu/libphilprac/ (2015)

17. J. Green, G. Nelson, A.J. Martin, H. Marsh, International Education Journal 7(4), 534 (2006)

18. D. H. Lim, H. J. Kim, Journal of Educational Technology Systems 31(4), 423 (2003) 